Marine Biology

Volume 151, Number 6 / juillet 2007: 2207-2215

http://dx.doi.org/ 10.1007/s00227-007-0655-7

(C)2007 Springer Science+Business Media
Archimer, archive institutionnelle de l'Ifremer http://www.ifremer.fr/docelec/

\title{
Small-scale spatial and temporal interactions among benthic crustaceans and one fish species in the Bay of Biscay
}

\author{
Verena M. Trenkel ${ }^{1,{ }^{*}}$ François Le Loc' ${ }^{2,3}$ and Marie-Joëlle Rochet ${ }^{1}$
}

(1) Département EMH, IFREMER, Rue de l'lle d'Yeu, B.P. 21105, 44311 Nantes Cedex 03, France

(2) LEMAR UMR 6539 CNRS, IUEM, UBO, Technopole Brest-Iroise, 29280 Plouzané, France

(3) Present address: UR 070 RAP, IRD, Centre de Recherche Halieutique, B.P. 171, 34203 Sète Cedex, France

*: Corresponding author : verena.trenkel@ifremer.fr

\begin{abstract}
:
In the summer of 2004, a video survey was carried out in the northern part of the central mud bank (Grande Vasière) of the Bay of Biscay to study the small scale relationship between the dominant crustacean megafauna Nephrops norvegicus, Munida rugosa and Goneplax rhomboides and juvenile hake (Merluccius merluccius). Using a towed body, high-resolution videos were recorded in six sampling sites. Statistical modelling using generalised additive models (GAM) revealed variations in activity patterns for two species. More N. norvegicus were observed outside their burrows at dawn and somewhat at dusk (no observations during night) while G. rhomboides was less observed in the morning. In addition, reduced spatial overlap between G. rhomboides and N. norvegicus suggested reduced competition for food but also space as both are burrowing species. The observed temporal and spatial activity patterns may contribute to regulating assemblage structure as competing species may be actively foraging at different times and locations thus reducing direct competition.
\end{abstract}

Keywords: Benthos - Video - Variations in activity patterns - Competition 


\section{Introduction}

Temporal or spatial avoidance is one solution to the paradox of competitive exclusion. Whereas theory predicts that coexistence is not possible between two species competing for a common resource, communities are made of many competing species. But when there is overlap on one niche dimension there might be separation on another. Southwood (1996) reviews cases where animals of similar size and feeding habits are spaced out in time, seasonally or daily (several insect examples). Megabenthic communities consist of species exploiting a common habitat and sharing food sources. Within this general co-occurrence of trophically competing species, differences in small scale spatial distributions patterns might contribute to mitigate and reduce competition. Thus the perception of the structure of a megabenthic community might depend on the spatial scale but also on the temporal resolution of the observations.

The northern part of the continental shelf of the Bay of Biscay is covered by a sedimentary bank known as the Grande Vasière. The dominant decapoda megafauna consists of Nephrops norvegicus, Munida rugosa and Goneplax rhomboides. Stable isotope analysis (Le Loc'h and Hily 2005) and stomach content studies (Lagadère 1973; Christo 1998; Parslow-Williams et al. 2002) suggest that these species feed on the same sources, consisting of a wide range of benthic and epibenthic organisms such as fish, small decapods and polychaetes. The first two species, in particular $N$. norvegicus are scavengers that have been observed to feed on fisheries discards (Bergmann et al. 2002). Leocarcinus depurator is another less abundant decapod of this megabenthic community. It is a dominant scavenger (Bergmann et al. 2002; Catchpole et al. 2006), whose main prey seem to be amphipods (Freire et al. 1996). These trophic characteristics potentially make the four decapod crustaceans trophic competitors and in addition they might compete for space, in particular those digging burrows. Patterson (1984) when investigating the epifauna in the Irish Sea which included $N$. norvegicus and $L$. depurator, found that globally all species were spatially segregated though the segregation was stronger for detritivores compared to active predators such as the two decapods. He concluded that competition for food was probably less responsible for their observed spatial segregation.

The Grande Vasière is home to a commercially exploited $N$. norvegicus population, but also an important area for young Merluccius merluccius (Le Danois 1920; Poulard 2001; Kacher and Amara 2005). M. merluccius is the most wide spread and abundant bottom dwelling fish species in the Bay of Biscay (Bertrand 2004). Adult hake are generally piscivore, however juveniles feed on small crustaceans and from about $15 \mathrm{~cm}$ on larger crustaceans such as $M$. rugosa and from $30 \mathrm{~cm}$ on $N$. norvegicus although they only constitute a small part of the diet in the Northern Bay of Biscay (Guichet 1995). M. merluccius does not seem to prey on G. rhomboides, but N. norvegicus does to some degree (Christo 1998). So there is a weak predator-prey relationship between hake and two of the decapods. In general, $N$. norvegicus has few fish predators, while both $G$. rhomboides and M. rugosa are actively selected by a wide range of predators (Serrano et al. 2003).

The small scale spatial and temporal structure of the megabenthic community of the northern part of the Bay of Biscay has been little studied, with the exception of N. norvegicus. The main studies to date have concentrated on large scale temporal and spatial patterns (Glémarec 1969; Le Loc'h 2004) as well as trophic relationships (Le Loc'h and Hily 2005). N. norvegicus has a well established pronounced diel activity pattern, with emergence at sunrise and sunset, and reduced activity during the day (Oakley 1979; Chapman 1980; Aguzzi et al. 2003); the pattern is modulated by season and depth (Aguzzi et al. 2003; Aguzzi et al. 2004). Spatial aggregation of $N$. norvegicus burrows has been found to vary seasonally, with burrows spatially aggregated during summer and more randomly distributed during winter time (Tuck et al. 1994). G. rhomboides also lives in burrows which are somewhat shallower than those dug by N. norvegicus (Rice and Chapman 1971), and there is evidence from laboratory work that it is more active early at night (Atkinson 1974a). Similarly, L. depurator seem to be more active during the night (Patterson 1984) while there is evidence from a video study carried out by Nickell and Sayer (1998) that M. rugosa exhibits higher activity during the day. Furthermore $M$. rugosa does not dig its own burrows but uses those already present. We hypothesize that spatial or temporal separation in the presence of $N$. norvegicus and its prominent competitors for space, G. rhomboides and $M$. rugosa, and its competitors for prey, $M$. rugosa and $L$. depurator might reduce direct competition for food and space. 
In this paper we investigate this hypothesis from video observations on the Grande Vasière. We first study spatial and temporal patterns for each decapod crustacean species separately and then analyse the spatial interactions among the decapods and between them and $M$. merluccius to derive information on local co-occurrence and direct competition.

\section{Material and Methods}

\section{Field study}

In late July of 2004, a 4-day video survey using a towed body was carried out at six sites in the northern part of the Grande Vasière in the Bay of Biscay (Figure 1). Observations started at about 5 am (universal time code UTC) just before sunrise and ended at 7 pm (UTC) shortly after sunset. No observations were carried out during the night. At each site, linear transects were surveyed, about half the time in one direction and then a parallel transect in the opposite direction close to the first one (except site 5 where transects were not duplicated). Due to time constraints, the sampling design was unbalanced, as not all sites were surveyed at all times of the day and the surveyed areas differed up to a factor of two between sites (Table 1). All sites except site 1, which was slightly shallower, had depths around $100 \mathrm{~m}$. Sediment type was determined (Chassé and Glémarec 1976) from dried samples obtained with a Shipeck grab at 19 locations situated at either side of the video transects. Sites 3 and 4 are surrounded by rocks, hence difficult to trawl. Sampling duration varied between stations, from 2 hours to about 10 hours.

A Sony PD 150 colour video camera (34 opening angle) was mounted perpendicular to the sea floor on the towed body. It was equipped with two parallel lasers $15 \mathrm{~cm}$ apart (error $2 \mathrm{~mm}$ at distance of $4 \mathrm{~m}$ ) for measuring the size of animals. One 400 Watt light projector was fixed behind the camera. The distance of the towed body from the ground as well as the pitch, roll and orientation of the towed body were recorded every second. In addition, the GPS position at the back of the vessel was stored as a proxy for the position of the camera. This allowed to calculate the size of the surveyed area at any time-interval as well as the total survey area. All videos were stored on DVcam and later analysed using the video processing software package Adélie (Le Cornu 2002). Individuals were counted and identified visually. Using the known distance between parallel laser points, the size of $N$. norvegicus was measured on the screen and then translated into real size. Total body size was measured when possible or otherwise cephalothorax length $(\mathrm{CL})$ for individuals well visible in the burrow entrance. CL was transformed to total length (TL) using the relationship $\mathrm{TL}=3.3 \mathrm{CL}$ (C. Talidec, pers. com.).

The camera was towed at an average distance of $1.3 \mathrm{~m}$ (s.d. 0.3) from the bottom at an average speed of $0.77 \mathrm{~m} \mathrm{~s}^{-1}$ (s.d. 0.4) and an average pitch of 8.5 degrees (s.d. 3.4). Given the small and consistent pitch of the camera, it was ignored in the calculation of the observation field. The resulting average width of the observation field was $0.81 \mathrm{~m}$ (s.d. 0.19).

\section{Data analysis}

The sequences of video counts were divided into non-overlapping units of around $80 \mathrm{~m}^{2}$ (s.d. 13). The size of the chosen sampling unit is a compromise between the number of sampling units (762) and the average number of observations per unit $(0.2 \mathrm{~L}$. depurator, $0.7 \mathrm{~N}$. norvegicus, $0.9 \mathrm{M}$. rugosa and $2.7 \mathrm{G}$. rhomboides). Sequences where the towed body was too far from the sea floor or turbidity was too high for reliable identification, were excluded from the analysis.

Temporal variations and differences between sites were assessed separately for each species. Temporal variations were modelled by smooth functions of time of day using generalised additive models (GAM), similarly to Benoît and Swain (2003) when studying diel variations in catchability of groundfish. For a given species, the expected number of individuals $C_{i j}$ per sampling unit $i$ at site $j$ was modelled as

$$
E(C i j)=\mu_{i j}=\exp \left(\log \left(A_{i}\right)+\alpha+\beta_{j}+s\left(T_{i}\right)\right)
$$

where $A_{i}$ is the surface area of sampling unit $i$ and treated as a fixed offset in the model in order to correct for the small difference in surface area of each unit. $\beta_{\mathrm{j}}$ is a fixed site effect with six levels (one for each site) and $T_{i}$ is the sampling time at the beginning of each sampling unit (universal time UTC expressed as a decimal variable, e.g. 5.5 for 5:30 UTC). For the smooth function s(.), an 
anisotropic cubic regression spline was chosen. The random components of the counts $C_{i j}$ were assumed to follow a negative binomial distribution with expectation and variance given by

$E\left(C_{i j}\right)=\mu_{i j}$ and $\operatorname{Var}\left(C_{i j}\right)=\mu_{i j}+\left(\mu_{i j}\right)^{2} / k$

The negative binomial distribution is often used for modelling overdispersed count data (Welsh et al. 1996). Overdispersion is the result of individuals not being randomly distributed in space. If individuals were randomly distributed in space, the number per unit area would follow a Poisson distribution and $k=\infty$ in eq. (2). In practice $k>10$ corresponds to a random distribution. Thus the value of $\mathrm{k}$ provides information on the degree of aggregation in the spatial distribution of each species. The value of $\mathrm{k}$ is estimated from the data.

The hypotheses underlying the model in (1) are i) species distributions at each site are homogeneous, i.e. the mean of the negative binomial distribution does not vary in space within sites, ii) mean abundance is directly related to sampling surface area, justifying the use of area as offset, iii) temporal patterns are the same at all sites, iv) if animals are perturbed by the lights of the towed body, the disturbance is the same at all sites and times. The assumptions seem reasonable, but have to be kept in mind when interpreting the results.

Model fitting and automatic selection of the degrees of freedom (df) for the cubic regression splines $s($.$) , were performed using the mgcv package in R$ ( $R$ development Core Team 2003). The Bayesian information criterium (BIC) was used as selection criterion as it leads to smoother models compared to the classical Akaike information criteria (AIC). Technically this was achieved by inflating the degrees of freedom of the smooth function by a factor of log(number of observations)/2 in the generalised cross-validation algorithm of mgcv based on minimising the jackknifed squared prediction error as described in Wood and Augustin (2002). The degrees of freedom of the cubic regression spline expresses the amount of smoothness. For example, $\mathrm{df}=1$ would correspond to a linear effect of the sampling time. Model goodness-of-fit was checked by visual inspection of residual plots.

In order to evaluate the impact of individual sites on the estimated temporal patterns which could be a result of the unbalanced sampling design in conjunction with the fact that different sites had different temporal patterns, a jackknife procedure was used. For this, model 1) was fitted repeatedly by excluding the data from one site at a time. It was then checked whether the jackknifed fitted smooth functions lay within the confidence bands of the model fit obtained using all data. If this is the case, it can be considered that the unbalanced sampling design did not induce bias in the estimated temporal patterns.

The spatial distribution of species were investigated on two levels, within and between sites. Within sites the k parameter of the negative binomial distribution (eq 2) is a measure for the type of spatial distribution. Between sites, the mean predicted densities were compared at the time of day with maximum emergence as determined by the GAM models. The time of maximum emergence was chosen as it provides a better estimate of the actual presence of each species and allows to correct for the unbalanced sampling design.

Local interactions between species were studied using the Williamson overlap index (Williamson 1993) for each site separately. The spatial overlap between species $m$ and $n$ at site $j$ is estimated as

$O_{m, n}=\frac{\sum_{i}\left(C_{i, j}^{m} C_{i, j}^{n}\right) k_{j}}{\sum_{i} C_{i, j}^{m} \sum_{i} C_{i, j}^{n}}$

where $C_{i, j}^{m}$ is the number of individuals of species $m$ observed in sampling unit $i$ at site $j$ and there are $k_{j}$ sampling units. The overlap index is 1 if both species are distributed randomly with respect to each other, while it is $<1$ if there is less overlap and $>1$ if there is more, i.e. the two species occur together. Raw observations were used for these calculations, thus averaging any time related effects for each site. In order to assess the sensitivity of the overlap index to the observation scale, represented by the size of the sampling units $\left(80 \mathrm{~m}^{2}\right)$, the index was calculated for several sizes of 
sampling units by aggregating successive sampling units, thus obtaining estimates for units of 160 , $240 \mathrm{~m}^{2}$ etc. In order to test whether estimates indices were significantly different from one, a jackknife procedure was carried out by dropping one (aggregated) sampling unit and recalculating the index. If the value 1 was not found within the $5^{\text {th }}$ and $95^{\text {th }}$ percentiles of the jackknifed estimates, it was declared significantly smaller (-) or larger (+) than one, thus indicating avoidance $(-)$ or co-occurrence $(+)$.

\section{Results}

Spatial and temporal distributions

The number of observed and measured individuals of each species varied between sites (Table 2). Site 1 , which was surveyed during late morning, was dominated by G. rhomboides. The other sites resembled each other. The proportion of $N$. norvegicus seen completely outside the burrow varied between 50 and $70 \%$. For those seen at the burrow entrance, a number of them retreated into their burrows on approach.

Variations in activity patterns as a function of time of day were difficult to discern from the plots of raw density estimates due to between site variation and incomplete sampling of all sites at all times (Figure 2). However, the patterns became much clearer when looking at the fitted GAM models which took account of a fixed site effect (Figure 3). The temporal patterns were similar at most sites surveyed at the same time as the smooth functions obtained by dropping one site at a time lay generally within the $95 \%$ confidence bands of the relationships fitted using all data with the exception of the afternoon peak for $M$. rugosa. This peak was supported by the data from only one sampling site (site 3 ) and hence could be a site effect as well as a change in activity. From this analysis there is evidence for opposite activity patterns for $N$. norvegicus and $G$. rhomboides, as more individuals of the former were encountered around sunrise while it were significantly less for the later. In terms of the type of spatial distribution, G. rhomboides showed the lowest degree of spatial clustering ( $k=6.1$, see Figure 2) compared to the other three species which were strongly clustered in space; it also had the highest density.

Using the fitted models, species densities were then predicted for the time of day with maximum activity. The times of maximum activity were read from the graphs (Figure 3); 15:00 for $G$. rhomboides and 6:00 for $N$. norvegicus. As for $L$. depurator and $M$. rugosa no strong variations in activity were found, no predictions were carried out. The comparison between these predicted densities and those estimated as simple sample average densities (corrected for sampling unit area) showed that correcting for observation time of day can change density estimates (Figure 4). This was the case for three out of the six sites for both G. rhomboides and N. norvegicus. Obviously the difference between observed and predicted densities depended on the shape of the temporal activity pattern during the time period a site was surveyed with respect to the time of maximum emergence. Standard errors of model predicted density estimates were generally lower than those derived directly from the observations as the variability due to different times of the day is removed.

The pair-wise relationships between species densities was then explored, excluding $L$. depurator due to the small numbers observed (Figure 5). Again predicted densities for the time of highest occurrence were used for N. norvegicus and G. rhomboides. The results point towards a negative relationship between $G$. rhomboides and $N$. norvegicus, but given the small number of sites and the large variability, the correlation was not significant (rank-based correlation tests). Also shown is the relationship between mean length of $N$. norvegicus and average density. The largest individuals were found on site 1 , which had a rather low density.

The spatial overall indices were generally independent of observation scale (Table 3; Figure 6). At all sites and most tested scales, G. rhomboides and $N$. norvegicus avoided each other spatially (overlap index $<1$ ), just as at the site scale as shown by density estimates by site. For all other species couples spatial overlap indices were site and scale dependent. The spatial overlap indices showed that none of the studied decapod crustaceans ( $L$. depurator was excluded due to low number of observations) avoided M. merluccius or occurred together with it. Thus there was no spatial relationship between the dominant fish species and any of the dominant decapod crustaceans. 


\section{Discussion}

This study demonstrates in situ reduced activity of G. rhomboides around sunrise. In a previous laboratory study increased activity was only found early at night (Atkinson 1974a). The limitation of this study to day time, including the periods of sunrise and sunset, does not provide any information regarding a possible second night time peak. The observed activity pattern for $G$. rhomboides is in opposition to the pattern for N. norvegicus observed synchronously. In addition to this temporal shift in activity between the two species, evidence for spatial avoidance was found, though the identified spatial avoidance might at least partly be due to the reduced temporal overlap. As both species create burrows, competition for space seems to be the most likely explanation for the observed spatial avoidance. So these two species seem to be an example of spatial partial avoidance in a decapod community which could be due to competition for space. Maynou et al. (1996) found similar spatial fragmentation of a number of decapod crustaceans on the northwestern Mediterranean slope (145-705m).

Within a sampling site, spatial overlap indices were constant across analysis scales ranging from 240 to about $800 \mathrm{~m}^{2}$, while more variability was observed at the lowest scales $\left(80\right.$ and $\left.160 \mathrm{~m}^{2}\right)$. At these lowest scales, individual choice rather than species choice are probably dominating, which might reflect small scale habitat variability or interactions between individuals of different species. In contrast differences of spatial overlap were consistent and more important between sampling sites. Thus the somewhat arbitrary choice of the size sampling units for investigating spatial overlap did not lead to spurious results.

There was no clear relationship between the presence of $M$. rugosa and $N$. norvegicus, although both species were exhibiting similar clustered spatial distribution types. So if any trophic competition exists, it is probably modulated by the decrease in activity during the day shown only by $N$. norvegicus but not $M$. rugosa. The absence of change in activity is in contrast to the findings by Nickell and Sayer (1998) who report activity spurs for M. rugosa, mainly during daylight hours in all seasons. Thus, although $N$. norvegicus and $M$. rugosa might feed on the same prey as suggested in the literature (see introduction), on the Grande Vasière they might do so most likely in close spatial vicinity but at different times of the day, which reduces direct interactions but not competition for food.

As for the relationship between $M$. merluccius and three dominant decapod crustaceans, no evidence for any spatial avoidance or attraction was found. Furthermore M. merluccius was found to be randomly distributed in the study area with no clear variations in activity patterns (results not shown). It is most likely that the dominant decapod crustacean community and the dominant dermersal fish species have little interactions, with trophic fluxes passing through other less abundant demersal and benthic fish species (Serrano et al. 2003).

In terms of spatial distributions, $L$. depurator, $N$. norvegicus and $M$. rugosa were found to be strongly clustered (small value of $k$ for negative binomial distribution). For the first two species this is well known. Tuck et al. (1994) found associations between juvenile and adult $N$. norvegicus burrows as juveniles build their burrows by branching off from existing burrows. This leads to aggregation of burrows during the summer. Individuals then redistribute during the winter with the result that burrows become more randomly distributed. Tagging studies have shown that $N$. norvegicus move only locally (average distance $250 \mathrm{~m}$ ), thus maintaining spatial clustering once it is established (Chapman 1980). Burrows et al. (2003) found that over a $24 \mathrm{~h}$ period N. norvegicus stayed at a maximum distance of about $20 \mathrm{~cm}$ around their burrows. Spatial patching of $L$. depurator has been reported from several areas, including the Mediterranean Iberian coast, where its presence was related to preferred sediment grain size (Rufino et al. 2004). Compared to the other three species, individuals of G. rhomboides were somewhat less clustered in space although not completely randomly distributed. Clumping of $G$. rhomboides burrows has been observed in a Scottish loch (Atkinson 1974b), although this is only an indication for spatial clustering of mobile individuals.

Mean length of $N$. norvegicus varied significantly between sampling zones. Tuck et al. (1997) have reported lower individual growth at higher densities for this species. However, no clear relationship with local density was found in this study. Mean length was highest in site 1, the more shallow station. Next in mean length were sites 3 and 4 which are little exploited by commercial trawling due to being surrounded by rocky patches. Abelló et al. (2002) explained variations in mean length 
of $N$. norvegicus across the Northern Mediterranean coast by local differences in fishing pressure. Thus, the observed differences in mean length could be due to variations in fishing pressure and/or habitat differences. Further studies need to be carried out to confirm this hypothesis.

In conclusion, this study showed variations in spatial and temporal activity patterns in the mega fauna community on the Grande Vasière. It supports the hypothesis that these activity patterns have an effect on regulating assemblage structure as some competing species may be actively foraging at different times or locations thus relying on the same food resources without direct interspecific interactions.

\section{Acknowledgement}

We would like to thank our colleagues J.F. Cadiou, A.-G. Allais, J.L. Michel, A. Przybicin, X. SaintLaurent and $Y$. Denis for preparing and running the video equipment. On board assistance by $A$. Ollitraut and the crew of RV Côtes de la Manche is gratefully acknowledged. 


\section{References}

Abelló P, Abella A, Adamidou A, Jukic-Peladic S, Maiorano P, Spedicato MT (2002) Geographical patterns in abundance and population structure of Nephrops norvegicus and Parapenaeus logirostris (Crustacea: Decapoda) along the European Mediterranean coasts. Scientia Marina 66(Suppl. 2): 125-141

Aguzzi J, Company JB, Sardà F (2004) Feeding activity rhythm of Nephrops norvegicus of the western Mediterranean shelf and slope grounds. Marine Biology 144: 463-472

Aguzzi J, Sardà F, Abelló P, Company JB, Rotllant G (2003) Diel and seasonal patterns of Nephrops norvegicus (Decapoda: Nephropidae) catchability in the western Mediterranean. Marine Ecology Progress Series 258: 201-211

Atkinson RJA (1974a) The activity rhythm of Goneplax rhomboides (L.). Mar. Behav. Physiol. 2: 325-335

Atkinson RJA (1974b) Spatial distribution of Nephrops burrows. Estuarine, Coastal and Shelf Science 2: 171-176

Benoît HP, Swain DP (2003) Accounting for length- and depth-dependent diel variation in catchability of fish and invertebrates in an annual bottom-trawl survey. ICES Journal of Marine Science 60: 1298-1317

Bergmann M, Wieczorek SK, Moore PG, Atkinson RJA (2002) Utilisation of invertebrates discarded from the Nephrops fishery by variously selective benthic scavengers in the west of Scotland. Marine Ecology Progress Series 233: 185-198

Bertrand JAE (2004) L'état des communautés exploitées au large des côtes de France. IFREMER

Burrows MR, Robb L, Nickell LA, Hughes DJ (2003) Topography as a determinant of search paths of fishes and mobile macrocrustacea on the sediment surface. Journal of Experimental Marine Biology and Ecology 285-286: 235-249

Catchpole TL, Frid CL, Gray TS (2006) Importance of discards from the English Nephrops norvegicus fishery in the North Sea to marine scavengers. Marine Ecology Progress Series 313: $215-226$

Chapman CJ (1980) Ecology of juvenile and adult Nephrops The biology and management of lobsters Vol. II. Academia Press, Inc., pp 143-178

Chassé C, Glémarec M (1976) Principes généraux de la classification des fonds pour la

cartographie sédimentaire. Journal de Recherche en Océanographie 1: 1-11

Christo M (1998) Feeding ecology of Nephrops norvegicus (Decapoda: Nephropidae). Journal of Natural History 32: 1493-1498

Freire J, Sampedro MP, González-Gurriarán E (1996) Influence of morphometry and biomechanics on diet selection in three portunid crabs. Marine Ecology Progress Series 137: 111-121

Glémarec M (1969) Les peuplements benthiques du plateau continental Nord-Gascogne. Thèse de Doctorat d'Etat

Guichet R (1995) The diet of European hake (Merluccius merluccius) in the northern part of the Bay of Biscay. ICES Journal of Marine Science 52: 21-31

Kacher M, Amara R (2005) Distribution and growth of 0-group European hake in the Bay of Biscay and Celtic Sea: a spatial and inter-annual analyses. Fisheries Research 71: 373-378

Lagadère J-P (1973) Distribution des décapodes dans le sud du Golfe de Gascogne. Rev. Trav. Inst. Pêches marit. 37: 77-95

Le Cornu F (2002) ADELIE: outils de post-traitement des données des engins sous-marins

Le Danois E (1920) Le merlu. Office Scientifique et Technique des Pêches Maritimes 2: 1-32

Le Loc'h F (2004) Structure, fonnctionement, évolution des communautés bentique des fond meubles exploités du plateau continental Nord Gascogne, Brest

Le Loc'h F, Hily C (2005) Stable carbon and nitrogen isotope analysis of Nephrops norvegicus/Merluccius merluccius fishing grounds in the Bay of Biscay (Northeast Atlantic). Canadian Journal of Fisheries and Aquatic Sciences 62: 123-132

Maynou F, Conan GY, Cartes JE, Company JB, Sardà F (1996) Spatial structure and seasonality of decapod crustacean populations on the northwestern Mediterranean slope. Limnology and Oceanography 41: 113-125

Nickell LA, Sayer MDJ (1998) Occurence and activity of mobile macrofauna on a sublittoral reef: diel and seasonal variation. Journal of the Marine Biological Association U. K. 78: 1061-1082

Oakley SG (1979) Diurnal and seasonal changes in the timing of peak catches of Nephrops norvegicus reflecting changes in behaviour. In: Naylor E, Hartnoll RG (eds) Cyclic phenomena in marine plants and animals. Pergamon Press, Oxford, pp 367-373 
Parslow-Williams P, Goodheir C, Atkinson RJA, Taylor AC (2002) Feeding energetics of the Norway lobster, Nephrops norvegicus in the Firth of Clyde, Scotland. Ophelia 56: 101-220

Patterson KR (1984) Distribution patterns of some epifauna in the Irish Sea and their ecological interactions. Marine Biology 83: 103-108

Poulard J-C (2001) Distribution of hake (Merluccius merluccius, Linnaeus, 1758) in the Bay of Biscay and the Celtic sea from the analysis of French commercial data. Fisheries Research 50: $173-187$

Rice AL, Chapman CJ (1971) Observations on the burrows and burrowing behaviour of two muddwelling decapod crustaceans, Nephrops norvegicus and Goneplax rhomboides. Marine Biology 10: 330-342

Rufino MM, Maynou F, Abelló P, Yule AB (2004) Small-scale non-linear geostatistical analysis of Liocarcinus depurator (Crustacea: Brachyura) abundance and size structure in a western Mediterranean population Marine Ecology Progress Series 276: 233-235

Serrano A, Velasco F, Olaso I, Sánchez F (2003) Macrobenthic crustaceans in the diet of demersal fish in the Bay of Biscay in relation to abundance in the environment. Sarsia 36-48

Southwood TRE (1996) Natural communities: structure and dynamics. Philosophical Transactions of the Royal Society London Series B 351: 1113-1129

Tuck ID, Atkinson RJA, Chapman CJ (1994) The structure and seasonal variability in the spatial distribution of Nephrops norvegicus burrows. Ophelia 40: 13-25

Tuck ID, Chapman CJ, Atkinson RJA (1997) Population biology of the Norway lobster, Nephrops norvegicus (L.) in the Firth of Clyde, Scotland - I: Growth and density. ICES Journal of Marine Sciences 54: 125-135

Welsh AH, Cunningham RB, Donnelly CF, Lindenmayer DB (1996) Modelling the abundance of rare species: statistical models for counts with extra zeros. Ecological Modelling 88: 297-308

Williamson CE (1993) Linking predation risk models with behavioural mechanisms: identifying population bottlenecks. Ecology 74: 320-331

Wood SN, Augustin NH (2002) GAMs with integrated model selection using penalized regression splines and applications to environmental modelling. Ecological Modelling 157: 157-177 
Table 1. Survey details and site characteristics. Sediment types: FM = fine mud; MS = muddy sand; MS+ = more sandy muddy sand.

\begin{tabular}{lllllll}
\hline Site & Date & Start UTC & End UTC & $\begin{array}{l}\text { Mean depth } \mathrm{m} \\
\text { (Range) }\end{array}$ & $\begin{array}{l}\text { Observed } \\
\text { area } \mathrm{m}^{2}\end{array}$ & $\begin{array}{l}\text { Sediment } \\
\text { type }\end{array}$ \\
\hline 1 & $27 / 7 / 2004$ & $09: 09: 25$ & $11: 03: 25$ & $76(64-79)$ & 5092 & $\mathrm{FM} / \mathrm{MS}$ \\
2 & $29 / 7 / 2004$ & $04: 57: 09$ & $11: 33: 39$ & $103(99-106)$ & 14219 & $\mathrm{MS}$ \\
3 & $29 / 7 / 2004$ & $14: 20: 39$ & $18: 59: 39$ & $106(104-108)$ & 10586 & $\mathrm{MS}$ \\
$4 \mathrm{a}$ & $28 / 7 / 2004$ & $05: 22: 25$ & $08: 32: 40$ & $107(106-109)$ & 9401 & $\mathrm{FM} / \mathrm{MS}$ \\
$4 \mathrm{~b}$ & $30 / 7 / 2004$ & $09: 29: 54$ & $12: 23: 54$ & & & \\
5 & $30 / 7 / 2004$ & $05: 11: 54$ & $08: 17: 09$ & $106(105-108)$ & 5884 & $\mathrm{FM}$ \\
6 & $28 / 7 / 2004$ & $09: 07: 25$ & $19: 45: 54$ & $105(101-108)$ & 13461 & $\mathrm{MS} / \mathrm{MS}+$ \\
\hline
\end{tabular}


Table 2. Number of observations per site.

\begin{tabular}{llllllll}
\hline \multicolumn{1}{c}{ Site } & & & & & & \\
\hline Species & 1 & 2 & 3 & 4 & 5 & 6 & Total \\
\hline Counted & & & & & & & \\
Goneplax rhomboides & 469 & 463 & 371 & 325 & 110 & 308 & 2046 \\
Liocarcinus depurator & 24 & 32 & 18 & 35 & 19 & 30 & 158 \\
Merluccius merluccius & 0 & 18 & 10 & 31 & 89 & 154 & 302 \\
Munida rugosa & 3 & 56 & 315 & 161 & 55 & 104 & 694 \\
N. norvegicus in entrance & 3 & 30 & 25 & 54 & 9 & 55 & 176 \\
N. norvegicus outside burrow 4 & 70 & 22 & 113 & 22 & 131 & 362 \\
Measured & & & & & & & \\
N. norvegicus & 4 & 52 & 22 & 129 & 22 & 131 & 360 \\
\hline
\end{tabular}


Table 3. Signs of test for spatial overlap index by site and species couple for three spatial levels:

$1=80 \mathrm{~m}^{2}, 2=400 \mathrm{~m}^{2}$ and $3=800 \mathrm{~m}^{2}$. '+': index $>1$; '-‘ index $<1$

Na: no observations.

G. rhomb. - M. merl. -M. rugosa -M. rugosa -M. rugosa -G. rhomb. SiteN. norveg. N. norveg. N. norveg. G. rhomb. M. merl. M. merl.

\begin{tabular}{lllllllllllllllllll}
\hline & 1 & 2 & 3 & 1 & 2 & 3 & 1 & 2 & 3 & 1 & 2 & 3 & 1 & 2 & 3 & 1 & 2 & 3 \\
\hline 1 & - & 1 & 1 & na & na & $\mathrm{Na}$ & + & 1 & 1 & + & + & + & na & na & na & na & na & na \\
2 & - & - & - & + & 1 & 1 & - & - & 1 & + & + & + & + & + & + & + & + & + \\
3 & - & - & 1 & - & 1 & + & + & + & 1 & - & 1 & + & - & - & - & - & - & - \\
4 & - & - & - & - & - & - & + & + & 1 & - & - & 1 & 1 & 1 & 1 & + & + & + \\
5 & - & - & - & + & + & + & - & + & + & + & + & + & + & + & + & - & + & + \\
6 & - & - & 1 & + & + & + & 1 & 1 & + & - & + & + & - & 1 & + & 1 & $1+$ & + \\
\hline
\end{tabular}




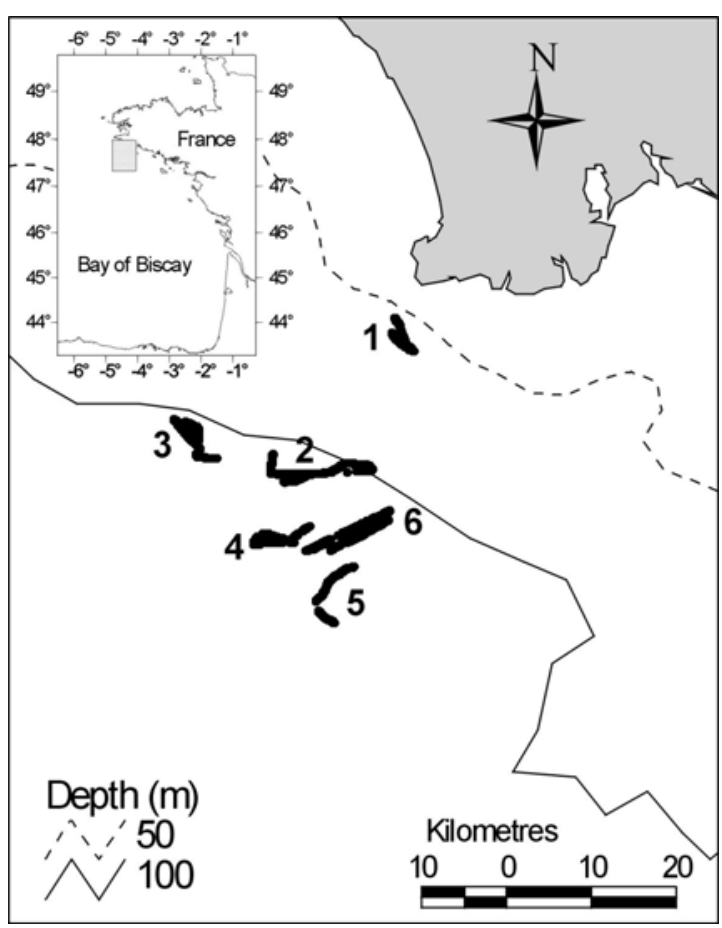

Figure 1. Location of sampling sites and video transects. 


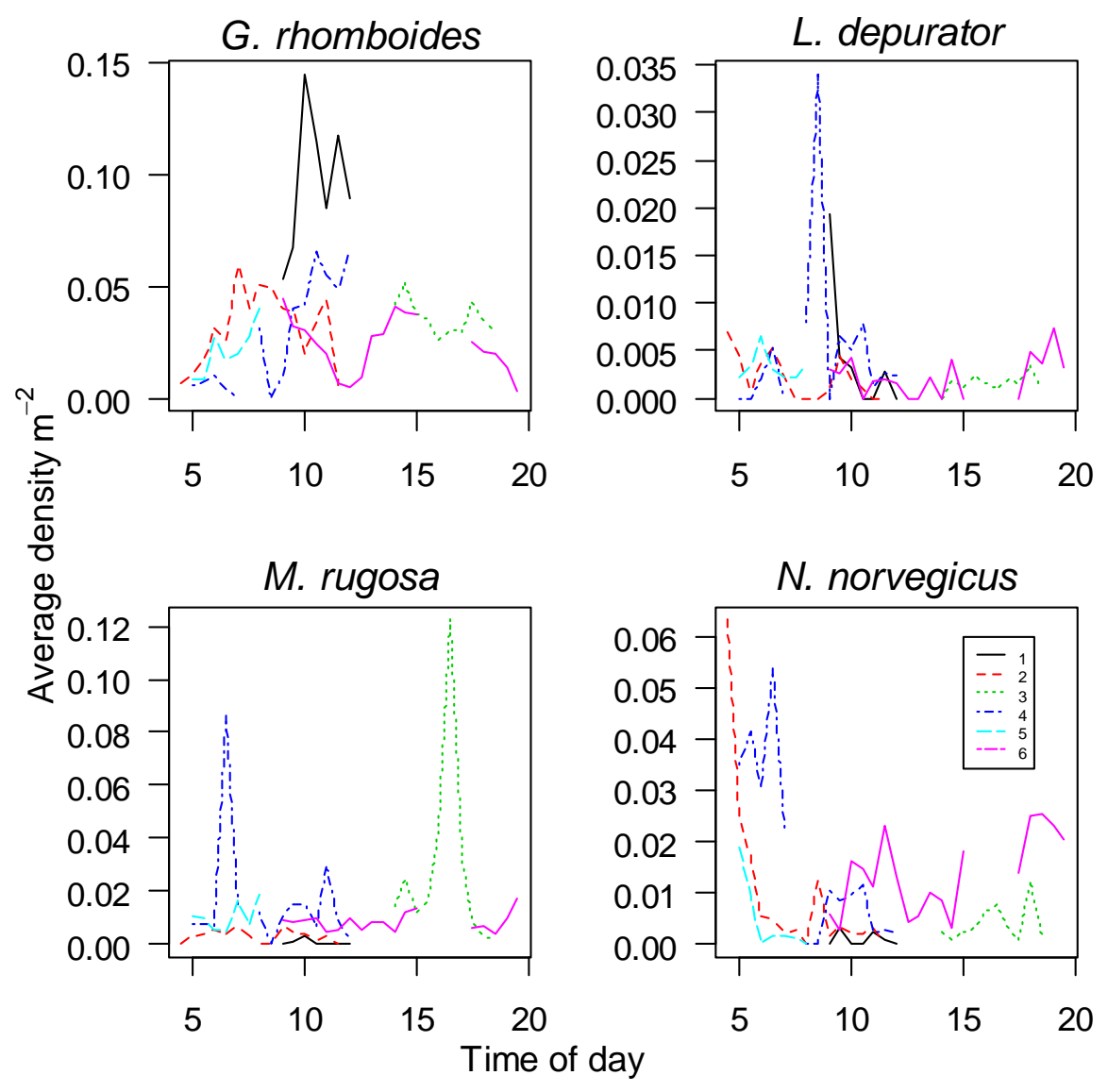

Figure 2. Average observed densities per half hour by time of day (universal time) for each sampling site. 
G. rhomboides $\mathrm{k}=6.1$

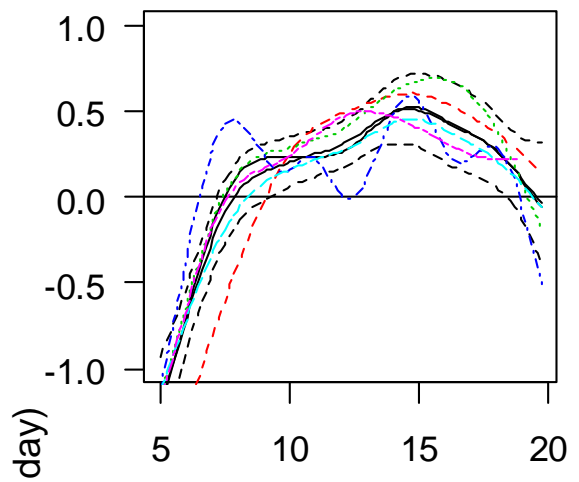

L. depurator $\mathrm{k}=1.0$

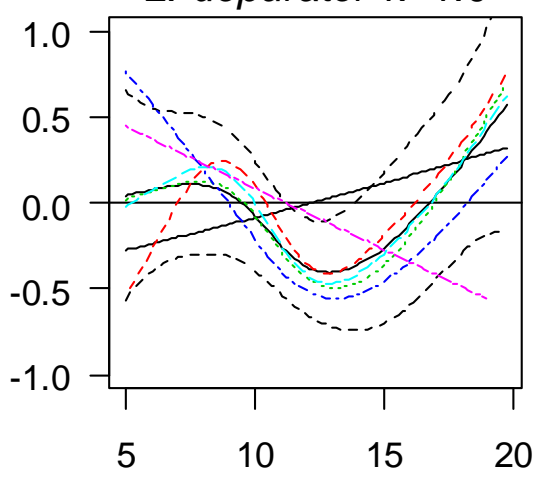

N. norvegicus $\mathrm{k}=2.0$

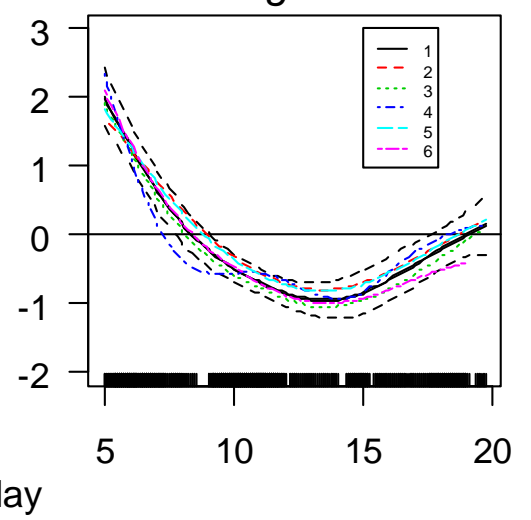

Figure 3. Smooth functions for time of day (universal time expressed as decimal value) with $95 \%$ confidence bands for GAM models for counts. There is no time of day effect when the zero line is included in the confidence bands. Colour lines indicate the average smooth functions obtained when one site at a time is dropped from the analysis (jackknife procedure). $\mathrm{k}$ is the overdispersion parameter of the fitted negative binomial distribution. The inset in the last figure indicates the timing of observations. 
G. rhomboides

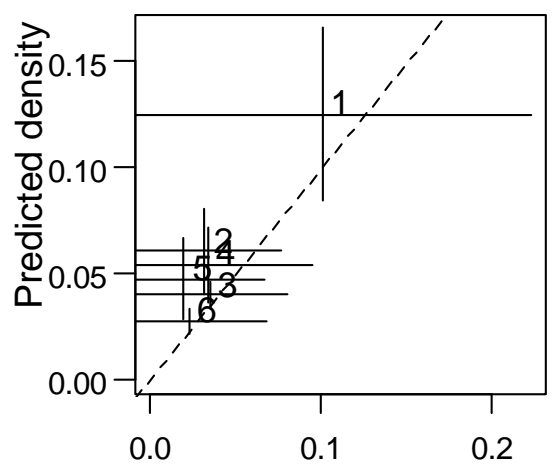

N. norvegicus

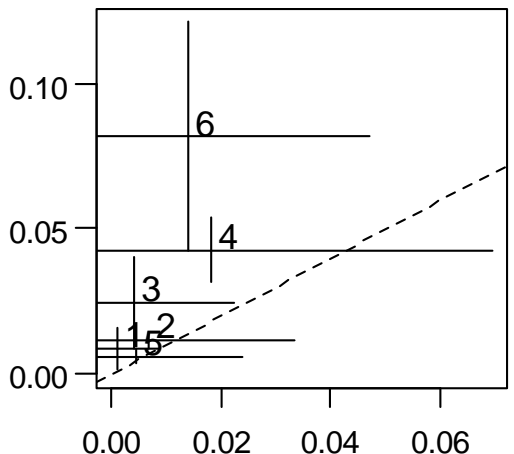

Average observed density

Figure 4. Comparison of model predicted species density $\left(\mathrm{m}^{-2}\right)$ at time of day of maximum activity with density estimated as simple sample average for each sampling site (numbers). Lines indicate \pm 2 standard deviations. Dashed diagonal line indicates equal density estimates. 

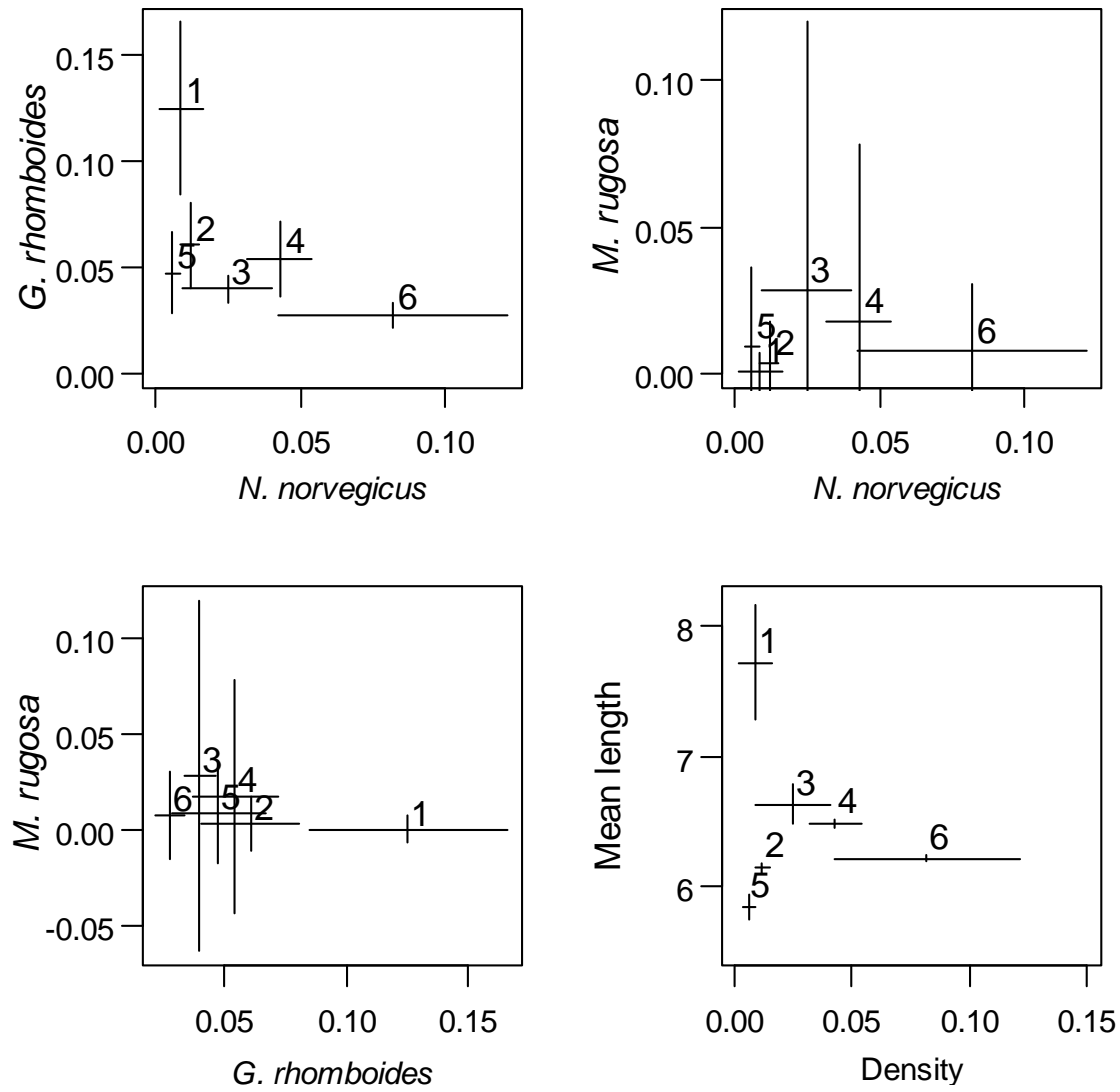

Figure 5. Inter-species relationships of model predicted or observed species densities per sampling site (numbers). Predicted densities $\left(\mathrm{m}^{-2}\right)$ at time of day with maximum activity for $\mathrm{G}$. rhomboides and $N$. norvegicus. Lines indicate \pm 2 standard deviations. Lower right panel $N$. norvegicus average length versus density. 

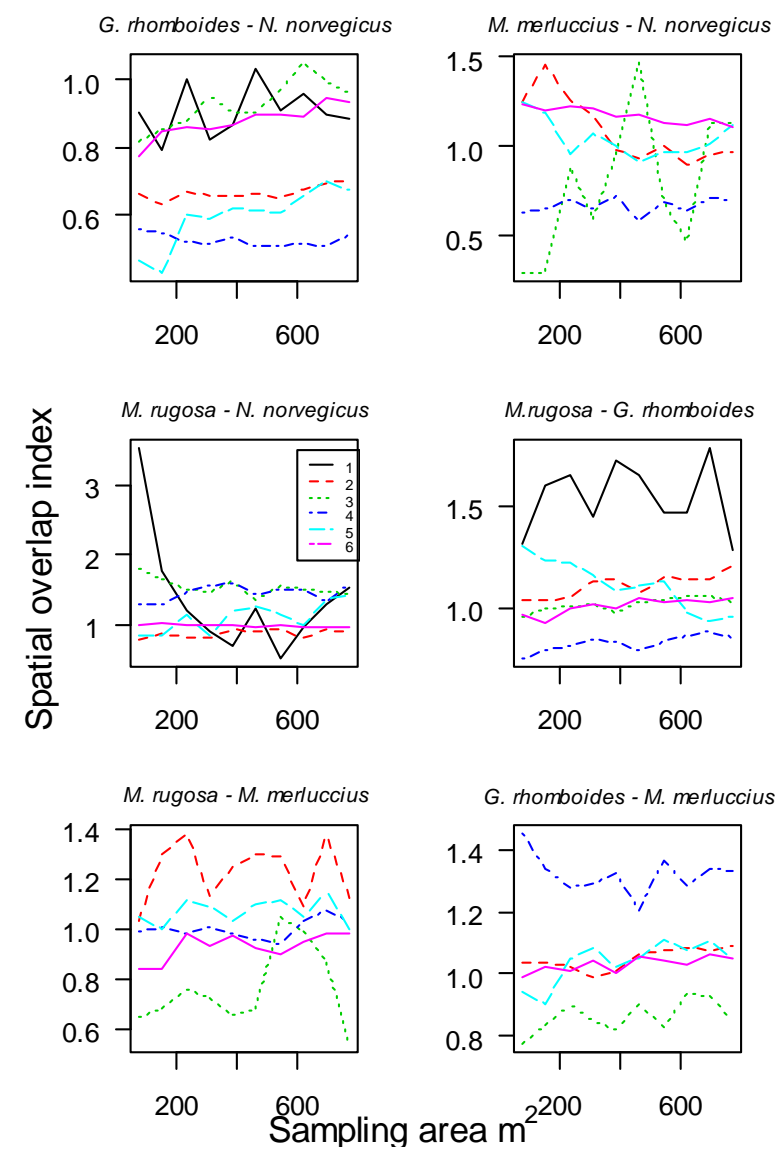

Figure 6. Pair-wise spatial overlap index by site (separate line per site) as a function of the surface area of the sampling unit. 